\title{
Rethinking the critical period for language: New insights into an old question from American Sign Language*
}

RACHEL I. MAYBERRY

Department of Linguistics, University of California San Diego ROBERT KLUENDER

Department of Linguistics, University of California San Diego

(Received: April 14, 2018; accepted: April 15, 2018; first published online 13 June 2018)

We thank the commentators for their thoughtful critiques, which we found both insightful and stimulating to our own thinking. Our first response is that, while debates about the CPL in theoretical contexts are important, the vigor and intensity of these debates should not overshadow the fact that the main goal of our article was to highlight a finding of vital importance: Sufficient language input in early childhood matters deeply because it has long-term consequences (Lillo-Martin, 2018). Woll sums up this point both succinctly and poignantly in her report of a similar case of very late L1 exposure in adulthood who had decades of experience: "For a [deaf] child who, even in the context of early intervention, does not acquire a spoken language, the danger is that they will never have native-like mastery of any L1." This is what truly matters. Our hope is that our keynote article and the accompanying commentaries might have a positive effect on clinical practice, educational policy, and even parental choice in this regard. In what follows, we discuss the main issues arising from the commentaries. First we note the points of agreement followed by a clarification of what we did not claim in our article. Researchers continue to debate what the shape of the AoA function looks like and its theoretical implications, which we address third. We then address the issues raised as to whether late L1 acquisition and late L2 learning differ in degree or kind, and last we discuss what we mean when we say that language acquisition during post-natal brain growth creates the capacity to learn language.

\section{Points of agreement}

The good news is that there is widespread agreement among language researchers about the CPL. Until recently, to our knowledge, no one has questioned that

\footnotetext{
* The research reported in this publication with ASL signers was supported in part by NIH grant R01DC012797. The content is solely the responsibility of the authors and does not necessarily represent the official views of the National Institutes of Health.
}

there is a steady decline in ultimate attainment the longer that exposure to any language - first, second, or $\mathrm{N}^{\text {th }}$ - is delayed over the childhood years. This consensus may be in need of modification in light of the large-scale findings reported in Hartshorne, Tenenbaum, and Pinker (in press) with regard to L2 syntactic learning ability, as cited by Birdsong and Quinto-Pozos in their commentary. There are also questions about the exact slope of this decline at different levels of linguistic analysis (BleyVroman, 2018; Lillo-Martin, 2018; Long \& Granena, 2018; Veríssimo, 2018). However, there seems to be no dispute about the general phenomenon and that it affects sign language too (Bialystok \& Kroll, 2018; Birdsong \& Quinto-Pozos, 2018; Bley-Vroman, 2018; DeKeyser, 2018; Hyltenstam, 2018; Lillo-Martin, 2018; Veríssimo, 2018; White, 2018). This in and of itself is a significant advance over Lenneberg's (1967) original hypothesis, which made no such prediction, and we should not lose sight of this fact. Indeed, research conducted by several of the commentators helped establish the finding, and for this we can all be thankful. At the same time we recognize that this piece of scientific convergence has not made its way into public discourse, which behooves us to redouble our outreach efforts.

A major point of disagreement among the commentators centers on the question of whether there is a similar steady decline across the adult years. Regardless of which answer ends up being correct, we need to bear in mind what is at stake. Adults (at least those with a first language established during childhood) will simply continue to muddle through, learning an additional language one way or the other as they have always done. As White puts it, the L2 " [ $\ldots]$ acquisition task involves coming up with a linguistic system that allows the learner to use the L2 (in comprehension and production). The task is NOT to arrive at a grammar identical to that of a native speaker." We would add that the $\mathrm{L} 1$ acquisition task is to come up with grammar in the first place, and that the ability to do so declines sharply the longer the child matures without language. Not all commentators agreed, however, about the differences between these two

Address for correspondence:

Rachel Mayberry, Ph.D., Department of Linguistics, University of California San Diego

rmayberry@ucsd.edu 
learning situations, which we address in detail below. Before discussing the shape and interpretation of the L2 AoA function, and comments about the L1 AoA function, we wish to set the record straight with regard to what we did not claim in our keynote article.

\section{What we did not claim}

For the sake of clarity, we would like to disavow certain positions that have been attributed to us in some of the commentaries, but that we do not in fact hold: Namely, that language learning ability functions flawlessly in adulthood, that L1 and L2 learning are the same, that L2 learners consistently perform on par with native speaker or signer controls, that all L2 learners attain near-native levels of proficiency, or that there are no differences between near-native and native-like language ability (Abrahamsson, 2018; Hyltenstam, 2018; Birdsong \& QuintoPozos, 2018). Some of these misconceptions may have arisen from our discussion of the possibility of L2 learners acquiring a native-like accent in section 2.1 'Phonological Effects.' As native-like pronunciation has often been touted as the sine qua non of critical period studies, we chose to focus precisely on this aspect of $\mathrm{L} 2$ acquisition in some detail in order to ascertain the extent to which it may, in fact, be at all possible. In this vein, we hasten to add that the $4 \%$ figure cited in a footnote, which several commentators mentioned (Abrahamsson, 2018; Lillo-Martin, 2018; Long \& Granena, 2018), was merely the lowest percentage of participants claimed to have performed within native speaker accent norms by the authors of any of the L2 pronunciation studies that we reviewed. We fully recognize the limitations of subjective assessments of accent, which is why we also included acoustic studies of pronunciation in our review. By no means did we intend to claim that $4 \%$ of $\mathrm{L} 2$ learners in the studies we reviewed demonstrate equivalent proficiency to native speakers at all levels of linguistic analysis, nor that $4 \%$ of all L2 learners perform at native levels. Rather, we explicitly stated that "[w]e are not claiming [native-like accent] to be the norm in L2 acquisition. To the contrary, everyone is anecdotally aware of the difficulty of achieving native-like pronunciation in a language acquired after childhood."

Some commentators also came away with the impression that - because we stated in our keynote article that "there is no animal model with which to study a CP for language (CPL)" - we must believe that the study of neuronal mechanisms underlying $\mathrm{CP}$ plasticity in various animal species is irrelevant to studies of the CPL (Reh, Arredondo \& Werker, 2018). To the contrary, we find such studies vitally important - and in fact cited one such study in our keynote article that showed effects of both critical period social isolation and corresponding knockout experiments in mice on oligodendrocyte maturation/myelination (Makinodan, Rosen, Ito \& Corfas,
2012). The relevance of this animal study is that myelination has been demonstrated to persist into the third decade of human life (Miller, Duka, Stimpson, Schapiro, Baze, McArthur, Fobbs, Sousa, Sestan, Wildman, Lipovich, Kuzawa, Hof \& Sherwood, 2012) and post-critical period L2 learning has been suggested to enhance myelination in college age populations (as measured by increases in fractional anisotropy and decreases in radial diffusivity) and thereby expand "the functionality of networks involved in learning by altering the underlying anatomy" (Schlegel, Rudelson \& Tse, 2012, p. 1669). Moreover, even studies of adult songbirds have demonstrated plasticity of vocal learning late in life. After deafening and recovery from hair cell destruction, adult domesticated society finches were not only able to relearn their songs, but these relearned songs more closely matched those of cagemates with which they were housed during recovery than their own original songs before deafening (Woolley \& Rubel, 2002). Thus the claim that "the evolutionary function of a CP is [not] to develop language-learning skills to be utilized beyond the closure of the $\mathrm{CP}$, no more than the function of a CP for birdsong is for the bird to develop skill for future birdsong learning" (Abrahamsson, 2018) cannot stand, at least for this particular species.

\section{The shape of the L2 AoA function}

One aspect of our keynote article that elicited comments from the greatest number of commentators concerned the shape of the AoA function, whether the linearity of the documented decline in ultimate attainment across the lifespan is continuous or discontinuous, and whether this decline reflects biological, L1 entrenchment, or socioenvironmental factors including L2 input (Bialystok \& Kroll, 2018; Birdsong \& Quinto-Pozos, 2018; DeKeyser, 2018; Hyltenstam, 2018; Long \& Granena, 2018; Newport, 2018; Veríssimo, 2018). Unsurprisingly, these are the commentators who have conducted studies investigating these questions. Opinions range all the way from the conclusion that there is no critical period at all (Bialystok $\&$ Kroll, 2018) to the conclusion that there are multiple critical periods with different age cutoffs for different linguistic phenomena (Bley-Vroman, 2018; Lillo-Martin, 2018; Long \& Granena, 2018; Veríssimo, 2018).

Here we flesh out some of the ideas in our keynote article that we were unable to elaborate on for lack of space. First and foremost, we emphasize that we are, for the most part, consumers rather than producers of $\mathrm{L} 2 \mathrm{AoA}$ research, and therefore come to this literature as interested but reasonably dispassionate observers. One inference that seems apparent to us, as alluded to in our original article, is that it would be desirable for the field to agree on how much of a difference (in variance accounted for) is sufficient to warrant choosing one alternative hypothesis over the other. 
The problem is exemplified by the analytical and interpretative differences across several of the L2 studies we reviewed. For example, Johnson and Newport (1989) reported correlation coefficients of -.77 for one linear function across all participants in their study with AoAs of 3-39 years, but of -.87 for participants with AoAs of 3-15 years, and no significant correlation for participants with AoAs of 17-39 years. Reanalyzing the data, Elman, Bates, Johnson, Karmiloff-Smith, Parisi, and Plunkett (1996) reported that Johnson and Newport's two linear functions accounted for $39.25 \%$ of the variance in the distribution, while a curvilinear function accounted for $63.1 \%$. As another example, when restricting the range of AoAs to 7-18 years in their analyses of morphosyntactic ability, Flege, Yeni-Komshian, and Liu (1999) reported that a sigmoid function accounted for $5 \%$ more of the variance than did a linear function, and conceded that this might be evidence for a discontinuity around an AoA of 12 years, although they also found linear correlations on either side of the 12-15 age range, with a more robust correlation before than after. In contrast, Granena and Long (2013) reported better fits with regression models incorporating two versus no AoA breakpoints for phonology, morphosyntax, and lexis/collocation alike, but then conceded that "the increase in variance accounted for, even if significant, was only around $5 \%$. This could mean that the less complex (i.e. more parsimonious) model with no breakpoints is already a good enough fit to the data [...]" (pp. 326f). Note that both sets of authors argue against their own preferred hypotheses in this instance. We were also aware that when age at time of testing was partialed out in the DeKeyser, Alfi-Shabtay, and Ravid (2010) study, only L2 learners with an AoA of up to 18 years still showed a correlation with proficiency. This correlation disappeared when the group was split at age 12 (possibly for lack of statistical power, as the authors suggest), but mean scores on the grammaticality judgment task still differed significantly between those with an AoA above or below age 12. Our issue is that both the correlation and the mean split appear to be largely attributable to where the earliest cutoff was drawn in the data set, namely at age 18 . It is not clear that either would hold up if the cutoff point had been changed to age 15, or for that matter age 19: Namely, the scores of the three U.S. participants with an AoA of 19 fell squarely in the middle of the distribution for those with AoAs of 15 or below, and well above those of participants with AoAs of 16 or 17. Similar problems exist in the Israeli data set.

Beyond debates about the shape of the AoA function, however, there is the question of what counts as 'puberty'. As we noted in our original article, and discussed above, across L2 AoA studies, the cutoff points (for what might pass for puberty) span nearly a decade: age 12 (DeKeyser et al., 2010), age 15 (Flege et al., 1999), age 16 (Abrahamsson \& Hyltenstam, 2008, 2009), age 17
(Johnson \& Newport, 1989), age 18 (DeKeyser et al., 2010), and age 20 (Birdsong \& Molis, 2001). Obviously, the rate at which individuals reach sexual maturity varies widely from case to case, and if the goal is to fix a point at which childhood neural development officially ends, it might be worth trying to locate this point on an individual basis. This is not an academic exercise. It would parallel the Pena, Werker, and Dehaene-Lambertz (2012) study of premature babies in order to determine if the benchmarks of phonological organization in the first year of life are tied to neural development or to the extent of language exposure. This work shows that sensitivity to linguistic input, at least for phonological learning, is yoked to phases in brain development. As Newport points out in her commentary, we now know much more about the brain changes that occur throughout adulthood that may, or may not, relate to L2 AoA effects in adulthood. In their commentary, Reh, Arredondo, and Werker (2018) suggest that the slower maturation of the frontal lobe relative to the earlier maturation of posterior brain areas may play a role in L2 learning, as also proposed by Thompson-Schill, Ramscar, and Chrysikou (2009).

Several commentators (Abrahamsson, 2018; Hyltenstam, 2018; Veríssimo, 2018) suggested that the materials used to test L2 proficiency are often lacking in theoretical sophistication and empirical rigor, and that the results of such studies should be taken with a grain of salt. We could not agree more, not only with regard to studies of ultimate attainment, but also - and perhaps especially - in neuroimaging studies. L2 proficiency has been defined in mostly ad hoc ways in the literature. L2 researchers could avail themselves of already established, comprehensive and detailed systems for determining language proficiency levels, including near-native and native: the Interagency Language Roundtable (ILR) Oral Proficiency Interview (OPI), used across U.S. federal service agencies for decades now, and the Common European Framework of Reference (CEFR) for languages, in use within the EU since 1996. In fact, these two scales have been calibrated against each other for a decade now as well, so their neglect in $\mathrm{L} 2$ research is puzzling.

\section{Language measurement and cognitive factors in late $L 1$ acquisition}

The fact that sign languages are subject to AoA effects prompted several commentators to conclude that sign languages are just like spoken languages (Birdsong \& Quinto-Pozos, 2018; Bialystok \& Kroll, 2018; DeKeyser, 2018; Veríssimo, 2018) and we of course agree. We also agree with the commentators who pointed out that the stimuli and tasks for AoA studies need to be carefully selected to determine whether different critical periods may differentially affect varying levels or domains of linguistic structures (Abrahamsson, 2018; Lillo-Martin, 
2018; Veríssimo, 2018). In turn, these commentators would probably agree with us that the particular question under investigation and the formal linguistic descriptions available for the language under study determine how AoA experiments can be crafted. It is easy to lose sight of the fact that sign languages have only recently been distinguished from gesture and admitted into the family of human languages (Goldin-Meadow \& Brentari, 2015). Research detailing the grammar of sign languages, ASL in particular, remains in its infancy compared with the longavailable descriptions of, for example, English, German, Turkish, or Swedish. Our initial studies had the goal of determining whether AoA effects were apparent in ASL at all - hence, our use of global processing measures like shadowing or sentence memory (Veríssimo, 2018). While much progress has been made describing ASL grammar (Sandler \& Lillo-Martin, 2006), linguists disagree about such basic linguistic phenomena in ASL as syllabification, verb agreement, anaphora, or pronominal forms, among others (Frederiksen \& Mayberry, 2016; Lillo-Martin \& Meier, 2011; Wilbur, 2011). Such ambiguities in formal linguistic description make it difficult, but not impossible, to ask whether late L1 acquisition affects particular domains of ASL grammar more than others.

We agree that all of a person's language representations, which can include more than one language in more than one sensory-motor modality, come into play during language processing (Bialystok \& Kroll, 2018; Birdsong \& Quinto-Pozos, 2018). Our working definition of late L1 acquisition is that the learner has few linguistic representations available at the onset of his or her initial ASL exposure. Deaf ASL signers who have linguistic representations available to them in other languages and forms that were established in early life perform at levels closer to those of earlier learners than late L1 learners. We were able to observe this in our original AoA studies. For example, when the task became difficult, one deaf signer began to reproduce ASL sentences entirely in fingerspelling, which formed the primary basis of this individual's early education. Another participant began subvocalizing when the ASL sentence task became hard; this participant became deaf at age 4 rather than at birth. It was these observations of deaf participants using languages and forms other than ASL that led us to hypothesize that critical period primarily affects first language acquisition (Mayberry, 1993; Mayberry \& Lock, 2003; Mayberry, Lock \& Kazmi, 2002). We do not pre-screen potential participants for their ASL skills. Instead we screen them for early language experience according to self-report. Some individuals who self-report as late L1 learners are clearly more akin to late "quasi-L2 ASL" learners. We believe this accounts for the individual variation apparent in some of our studies (Emmorey, 2018).
In her commentary, Emmorey asks whether individual differences among late $\mathrm{L} 1$ learners might be due to varying levels of motivation or cognitive abilities. Although we have not attempted to measure it, the motivation of deaf individuals to learn ASL, including those who learn it after minimal childhood language experience, is extremely high. This is illustrated by the stories deaf signers tell about their ASL learning and how it has changed their lives (Valli, Lucas, Farb \& Kulick, 1992). The life transforming attributes of learning ASL are a common theme in ASL poetry and literature (Perlmutter, 2008). The logical problem with attributing attenuated levels of ASL development to working memory is that its development is known to be inextricably tied to language development (Gathercole \& Baddeley, 1993). Working memory further relates to the development of executive function, which is also correlated with level of language development (Botting, Jones, Marshall, Denmark, Atkinson \& Morgan, 2017; Hall, Eigsti, Bortfeld \& Lillo-Martin, 2017). In this sense, working memory and executive function might be considered as being comorbidities of acquiring a first language after early childhood.

With respect to general cognitive functioning, it is important to know that hundreds of studies of deaf individuals' IQ - spanning more than a century - have repeatedly found the deaf population to score within the normal range of the hearing population on non-verbal IQ scales, despite widespread language deprivation in this population (Braden, 1994; Mayberry, 2002). Among the cognitive skills tapped by various non-verbal IQ tasks, spatial cognition is a notable strength among late L1 learners. For example, many late L1 learners have excellent navigation and drawing skills. Consistent with spatial cognitive strengths, late L1 learners show greater proficiency with ASL classifier constructions that encode spatial relations in contrast to ASL syntactic constructions that do not (Boudreault \& Mayberry, 2006; Mayberry, Cheng, Hatrak \& Ilkbasaran, in preparation). These linguistic strengths begin to address the question of whether some aspects of linguistic structure are more sensitive to AoA than others (Bley-Vroman, 2018; LilloMartin, 2018; Long \& Granena, 2018; Veríssimo, 2018), an important question in need of further investigation.

The quantity and quality of linguistic input, in various cognitive domains, and education may interact with L1 AoA effects, as several commentators suggested (Birdsong \& Quinto-Pozos, 2018; Emmorey, 2018; Flege, 2018; Long \& Granena, 2018; Newport, 2018). We agree and note that studies of how linguistic frequency interacts with L1 AoA effects have yet to be conducted. The most common source of language input for deaf late learners is through education. Deaf late L1 learners who are able to attend school with other deaf signers receive more ASL input than those without such opportunities. The extent to which this increased input boosts ASL language levels 
remains to be investigated (Henner, Caldwell-Harris, Novogrodsky \& Hoffmeister, 2016).

Woll describes a case study of a deaf man, M, whose L1 acquisition began in his late 20s and who had 25 years of experience with British Sign Language. M's language skills are consistent with those of our case study, Martin, who began to acquire sign language as an L1 at age 21 and had 30 years of experience with ASL (Mayberry, Davenport, Roth \& Halgren, 2018). Both cases showed limited morphological and syntactic ability and reduced abilities to comprehend and produce sign language, British Sign Language for M and ASL for Martin. Notably, both individuals are described as having excellent navigation skills. Unlike Bialystok and Kroll, we do not interpret the fact that individuals such as these cases are able to learn some sign language as evidence against a critical period for language. A modicum of vocabulary assembled in utterances with sparse morphology or syntax does not, in our view, constitute a functional language system, just as the ability to detect light, and the edges of objects after cataract removal in adulthood does not indicate a functional visual system. Nor do we think that late L1 learners are similar to heritage language learners (Bialystok \& Kroll, 2018; Birdsong \& Quinto-Pozos, 2018; Lillo-Martin, 2018; White, 2018) for the simple reason that heritage language users have fully developed linguistic representations and processes available to them in the form of their dominant language.

\section{Creating the capacity to learn language}

A number of commentators noted that Johnson and Newport (1989) originally proposed two possible mechanisms to underlie AoA effects, maturation versus exercise. The later hypothesis is also referred to as the "use it or lose it" explanation (Abrahamsson, 2018; Bley-Vroman, 2018; DeKeyser, 2018; Hyltenstam, 2018; Veríssimo, 2018; White, 2018). While our research with deaf late L1 learners suggests that the capacity to learn language diminishes with age (Bley-Vroman, 2018; Hyltenstam, 2018; DeKeyser, 2018; Veríssimo, 2018), we think that a more accurate theoretical framing of the phenomenon is that a prolonged delay in language exposure leads to a diminished capacity to learn language. In the case of deaf late L1 learners, the infant brain was ready to interact with the environment linguistically, but the environment failed to yield the necessary language input. In his figure, Hyltenstam shows a steep decline in ultimate language outcome incorporating data from L2 learners with that of the late L1 learners reported in the literature. We think this figure summarizes these phenomena well, but our theoretical reframing would turn it upside down. All language learners begin with an intercept of zero. Reflecting the creation of language ability, individuals whose language experience begins in infancy show a steep upward trajectory in the acquisition of language structure. This language learning curve asymptotes at lower than native-speaker/signer levels, the older the onset of L2 learning. In addition, the probability that the learning curve will approach native-like levels declines sharply the longer the delay in L1 exposure. This framework illustrates the "hybrid" hypothesis proposed by Newport.

Studies of language acquisition in late L1 learners indicate that the outcome of language acquisition is not governed by cognitive maturation but by the cognitive processes of deciphering linguistic structure in synchrony with neural development. Despite being cognitively mature, adolescents acquiring language for the first time begin the process by learning vocabulary, which they subsequently combine into single predicate utterances. The older the age onset of L1 experience, the less likely the learner will progress to more complex morphological and syntactic structures (Cheng \& Mayberry, under review; Mayberry, Cheng, Hatrak \& Ilkbasaran, 2017). Although the infant brain shows activation in response to spoken language in the expected left hemisphere areas in response to language (Dehaene-Lambertz, Dehaene \& Hertz-Pannier, 2002), multiple neural changes that occur throughout childhood affect the brain language system as well. The infant brain matures from posterior to anterior regions, and this is evident in children's language processing too (Schlaggar, Brown, Lugar, Visscher, Miezin \& Petersen, 2002). During childhood the brain language system becomes more lateralized and consolidated (Berl, Mayo, Parks, Rosenberger, VanMeter, Ratner, Vaidya \& Gaillard, 2014). The brain language system also becomes more robustly connected over childhood. Dorsal pathways connecting language areas in the temporal and frontal lobes become increasing myelinated (Pujol, Soriano-Mas, Oritz, Sebastián-Gallés $\&$ Deus, 2006). Increased myelination of left hemisphere fiber tracts correlates with the onset of complex sentence comprehension in typically developing children during late childhood (Skeide, Brauer \& Friederici, 2016). Deaf signers who began to learn ASL after childhood show reduced myelination of these fiber tracts and show concomitant difficulty comprehending complex ASL sentences (Cheng, Roth, Halgren \& Mayberry, under review). Thus the act of learning language may trigger neural development throughout varying stages in the development of the brain language system. This scenario of reciprocal linguistic input effects on postnatal brain growth and vice versa would create the ability to learn language by enlarging the information processing capacity of the neurolinguistic system to recognize and manipulate linguistic representations. The task of L2 learning would thus be facilitated when a lexicon, grammar, and a neural language network are either being developed simultaneously or already 
in place. The task of L1 learning at older ages is impeded when the requisite neural architecture is not in place.

More research is required to determine the specific links between language acquisition and the development of the brain language system and the extent to which they are reciprocally causal. In this way, the study of this atypical, but unfortunately all too common, situation of late $\mathrm{L} 1$ acquisition among individuals born deaf promises to illuminate basic acquisitional and neurodevelopmental processes that together create the faculty of human language.

\section{References}

Abrahamsson, N. (2018). But first, let's think again! Bilingualism: Language and Cognition. doi: https://doi.org/ 10.1017/S1366728918000251

Abrahamsson, N., \& Hyltenstam, K. (2008). The robustness of aptitude effects in near-native second language acquisition. Studies in Second Language Acquisition, 30, 481-509.

Abrahamsson, N., \& Hyltenstam, K. (2009). Age of onset and nativelikeness in a second language: Listener perception versus linguistic scrutiny. Language Learning, 59(2), 249306.

Berl, M. M., Mayo, J., Parks, E. N., Rosenberger, L. R., VanMeter, J., Ratner, N. B., Vaidya, C. J., \& Gaillard, W. D. (2014). Regional differences in the developmental trajectory of lateralization of the language network. Human Brain Mapping, 35(1), 270-284. doi:10.1002/hbm.22179

Bialystok, E., \& Kroll, J. F. (2018). Can the critical period be saved? A bilingual perspective. Bilingualism: Language and Cognition. doi: https://doi.org/10. 1017/S1366728918000202

Birdsong, D., \& Molis, M. (2001). On the evidence for maturational constraints in second-language acquisition. Journal of Memory and Language, 44(2), 235-249.

Birdsong, D., \& Quinto-Pozos, D. (2018). Signers and speakers, age and attainment. Bilingualism: Language and Cognition. doi: https://doi.org/10.1017/S1366728918000226

Bley-Vroman, R. (2018). Language as "something strange". Bilingualism: Language and Cognition. doi: https: //doi.org/10.1017/S136672891800024X

Botting, N., Jones, A., Marshall, C., Denmark, T., Atkinson, J., \& Morgan, G. (2017). Nonverbal executive function is mediated by language: A study of deaf and hearing children. Child Development, 88(5), 1689-1700. doi:10.1111/cdev.12659

Boudreault, P., \& Mayberry, R. I. (2006). Grammatical processing in American Sign Language: Age of firstlanguage acquisition effects in relation to syntactic structure. Language and Cognitive Processes, 21(5), 608635. doi: 10.1080/01690960500139363

Braden, J. P. (1994). Deafness, Deprivation, and IQ. New York: Plenum Press.

Cheng, Q., \& Mayberry, R. I. (under review). The trajectory of variable word order acquisition in American Sign Language: Insights from adolescent first-language learners.
Cheng, Q., Roth, A., Halgren, E., \& Mayberry, R. I. (under review). Language pathways in deaf native signers and late L1 learners of ASL: Effects of modality and early language deprivation on brain connectivity for language.

Dehaene-Lambertz, G., Dehaene, S., \& Hertz-Pannier, L. (2002). Functional neuroimaging of speech perception in infants. Science, 298(5600), 2013-2015.

DeKeyser, R. (2018). The critical period hypothesis - a diamond in the rough. Bilingualism: Language and Cognition. doi: https://doi.org/10.1017/S1366728918000147

DeKeyser, R., Alfi-Shabtay, I., \& Ravid, D. (2010). Crosslinguistic evidence for the nature of age effects in second language acquisition. Applied Psycholinguistics, 31, 413438.

Elman, J. L., Bates, E., Johnson, M. H., Karmiloff-Smith, A., Parisi, D., \& Plunkett, K. (1996). Rethinking Innateness. Cambridge, MA: MIT Press.

Emmorey, K. (2018). Variation in late L1 acquisition? Bilingualism: Language and Cognition. doi: https://doi.org/10.1017/S1366728918000196

Flege, J. E. (2018). It's input that matters most, not age. Bilingualism: Language and Cognition. doi: https://doi. org/10.1017/S136672891800010X

Flege, J. E., Yeni-Komshian, G. H., \& Liu, S. (1999). Age constraints on second-language acquisition. Journal of Memory and Language, 41(1), 78-104. doi: 10.1006/Jmla.1999.2638

Frederiksen, A. T., \& Mayberry, R. I. (2016). Who's on First? Investigating the referential hierarchy in simple native ASL narratives. Lingua, 180, 49-68. doi:10.1016/j.lingua.2016.03.007

Gathercole, S. E., \& Baddeley, A. D. (1993). Working Memory and Language. Hove, New York: Psychology Press.

Goldin-Meadow, S., \& Brentari, D. (2015). Gesture, sign and language: The coming of age of sign language and gesture studies. Behavioral and Brain Sciences, 40, 1-82. doi:10.1017/S0140525X15001247

Granena, G., \& Long, M. H. (2013). Age of onset length of residence, language aptitude, and ultimate L2 attainment in three linguistic domains. Second Language Research, 29(3), 313-343.

Hall, M. L., Eigsti, I. M., Bortfeld, H., \& Lillo-Martin, D. (2017). Auditory Deprivation Does Not Impair Executive Function, But Language Deprivation Might: Evidence From a Parent-Report Measure in Deaf Native Signing Children. Journal of Deaf Studies and Deaf Education, 22(1), 9-21. doi:10.1093/deafed/enw054

Hartshorne, J. K., Tenenbaum, J. B., \& Pinker, S. (in press). A critical period for second language acquisition: Evidence from 2/3 million English speakers. Cognition.

Henner, J., Caldwell-Harris, C. L., Novogrodsky, R., \& Hoffmeister, R. (2016). American Sign Language Syntax and Analogical Reasoning Skills Are Influenced by Early Acquisition and Age of Entry to Signing Schools for the Deaf. Frontiers in Psychology, 07. doi:10.3389/fpsyg.2016.01982

Hyltenstam, K. (2018). Second language ultimate attainment: Effects of maturation, exercise, and social/psychological factors. Bilingualism: Language and Cognition. doi: https://doi.org/10.1017/S1366728918000172 
Johnson, J. S., \& Newport, E. L. (1989). Critical period effects in second language learning: The influence of maturational state on the acquisition of English as a second language. Cognitive Psychology, 21, 60-90.

Lenneberg, E. (1967). Biological Foundations of Language. New York: John Wiley \& Sons.

Lillo-Martin, D. (2018). Differences and similarities between late first-language and second-language learning. Bilingualism: Language and Cognition. doi: https://doi.org/10.1017/S1366728918000159

Lillo-Martin, D., \& Meier, R. P. (2011). On the linguistic status of 'agreement' in sign languages. Theoretical Linguistics, 37(3/4), 95-141. doi:10.1515/ THLI.2011.009

Long, M. H., \& Granena, G. (2018). Sensitive periods and language aptitude in second language acquisition. Bilingualism: Language and Cognition. doi: https://doi.org/10.1017/S1366728918000184

Makinodan, M., Rosen, K. M., Ito, S., \& Corfas, G. (2012). A critical period for social experience-dependent oligodendrocyte maturation and myelination. Science, 337(6100), 1357-1360. doi:10.1126/science.1220845

Mayberry, R. I. (1993). First language acquisition after childhood differs from second language acquisition: The case of American Sign Language. Journal of Speech and Hearing Research, 36(6), 1258-1270.

Mayberry, R. I. (2002). Cognitive development in deaf children: The interface of language and perception in neuropsychology. In S. J. Segalowitcz \& I. Rapin (Eds.), Handbook of neuropsychology (2 ed., Vol. 8, pp. 71-107).

Mayberry, R. I., Cheng, Q., Hatrak, M., \& Ilkbasaran, D. (2017). Late L1 learners acquire simple but not syntactically complex structures. Paper presented at the International Association for the Study of Child Language, Lyon, France.

Mayberry, R. I., Cheng, Q., Hatrak, M., \& Ilkbasaran, D. (in preparation). For arborized trees, plant early: How language deprivation affects syntactic development. Manuscript in preparation.

Mayberry, R. I., Davenport, T., Roth, A., \& Halgren, E. (2018). Neurolinguistic processing when the brain matures without language. Cortex, 99, 390-403. doi:10.1016/j.cortex.2017.12.011

Mayberry, R. I., \& Lock, E. (2003). Age constraints on first versus second language acquisition: Evidence for linguistic plasticity and epigenesis. Brain and Language, 87(3), 369384. doi: 10.1016/S0093-934x(03)00137-8

Mayberry, R. I., Lock, E., \& Kazmi, H. (2002). Linguistic ability and early language exposure. Nature, 417(6884), 38-38. doi: $10.1038 / 417038$ a

Miller, D. J., Duka, T., Stimpson, C. D., Schapiro, S. J., Baze, W. B., McArthur, M. J., Fobbs, A. J., Sousa, A. M., Sestan, N., Wildman, D. E., Lipovich, L., Kuzawa, C. W., Hof, P. R., \& Sherwood, C. C. (2012). Prolonged myelination in human neocortical evolution. Proceedings of the National Academy of Sciences of the USA, 109(41), 16480-16485. doi:10.1073/pnas.1117943109

Newport, E. L. (2018). Is there a critical period for L1 but not L2? Bilingualism: Language and Cognition. doi: https://doi.org/10.1017/S1366728918000305
Pena, M., Werker, J. F., \& Dehaene-Lambertz, G. (2012). Earlier speech exposure does not accelerate speech acquisition. Journal of Neuroscience, 32(33), 1115911163. doi:10.1523/JNEUROSCI.6516-11.2012

Perlmutter, D. M. (2008). Nobilior est vulgaris: Dante's hypothesis and sign language poetry. In K. A. Lindgren, D. DeLuca, \& D. Napoli (Eds.), Signs and Voices: Deaf culture, identify, language and arts (pp. 189-213). Washington, DC: Gallaudet University Press.

Pujol, J., Soriano-Mas, C., Oritz, H., Sebastián-Gallés, N., \& Deus, J. (2006). Myelination of language-related areas in the developing brain. Neurology, 66, 339343.

Reh, R. K., Arrendo, M. M., \& Werker, J. F. (2018). Understanding individual variation in levels of second language attainment through the lens of critical period mechanisms. Bilingualism: Language and Cognition. doi: https://doi.org/10.1017/S1366728918000263

Sandler, W., \& Lillo-Martin, D. (2006). Sign Language and Linguistic Universals: Cambridge University Press.

Schlaggar, B. L., Brown, T. T., Lugar, H. M., Visscher, K. M., Miezin, F. M., \& Petersen, S. E. (2002). Functional neuroanatomical differences between adults and schoolage children in the processing of single words. Science, 296(5572), 1476-1479.

Schlegel, A., Rudelson, J., \& Tse, P. (2012). White matter structure changes as adults learn a second language. Journal of Cognitive Neuroscience, 24(8), 16641670.

Skeide, M. A., Brauer, J., \& Friederici, A. D. (2016). Brain functional and structural predictors of language performance. Cerebral Cortex, 26(5), 2127-2139. doi:10.1093/cercor/bhv042

Thompson-Schill, S. L., Ramscar, M., \& Chrysikou, E. G. (2009). Cognition without control. Current Directions in Psychological Science, 18(5), 259-263.

Valli, C., Lucas, C., Farb, E., \& Kulick, P. (1992). ASL Pah!: Deaf students ' perspectives on their language. Silver Spring Md: Linstok Press.

Veríssimo, J. (2018). Sensitive periods in both L1 and L2: Some conceptual and methodological suggestions. Bilingualism: Language and Cognition. doi: https://doi.org/10.1017/S1366728918000275

White, L. (2018). Nonconvergence on the native speaker grammar: Defining L2 success. Bilingualism: Language and Cognition. doi: https://doi.org/10.1017/ S1366728918000214

Wilbur, R. B. (2011). Sign syllables. In M. v. Oostendorpp, C. Ewen, E. Hume, \& K. Rice (Eds.), The Blackwell Companion to Phonology (pp. 1-26): Blackwell Publishing.

Woll, B. (2018). The consequences of very late exposure to BSL as an L1. Bilingualism: Language and Cognition. doi: https://doi.org/10.1017/S1366728918000238

Woolley, S., \& Rubel, E. (2002). Vocal memory and learning in adult Bengalese finches with regenerated hair cells. The Journal of Neuroscience, 22(1), 7774-7787. 